\title{
Effects of the Morphology of the Electrode Nanostructures on the Performance of Dye-Sensitized Solar Cells
}

\author{
Nicholas N. Bwana $(\varangle)$ \\ Department of Computer Science, Mathematics, and Physics, The University of the West Indies, Cave Hill Campus, St. Michael, \\ Barbados \\ Received: 10 September 2008 / Revised: 29 October 2008 / Accepted: 29 October 2008 \\ CTsinghua Press and Springer-Verlag 2008. This article is published with open access at Springerlink.com
}

\begin{abstract}
This article reports the performances of dye-sensitized solar cells based on different working electrode structures, namely (1) highly ordered arrays of $\mathrm{TiO}_{2}$ nanorods, (2) highly ordered arrays of $\mathrm{TiO}_{2}$ nanotubules of different wall thicknesses, and (3) sintered $\mathrm{TiO}_{2}$ nanoparticles. Even though highest short-circuit current density was achieved with systems based on $\mathrm{TiO}_{2}$ nanotubules, the most efficient cells were those based on ordered arrays of $\mathrm{TiO}_{2}$ nanorods. This is probably due to the higher open-circuit photovoltage values attained with $\mathrm{TiO}_{2}$ nanorods compared with $\mathrm{TiO}_{2}$ nanotubules. The nanorods are thicker than the nanotubules and therefore the injected electrons, stored in the trap states of the inner $\mathrm{TiO}_{2}$ particles, are shielded from recombination with holes in the redox electrolyte at open-circuit. The high short-circuit photocurrent densities seen in the ordered $\mathrm{TiO}_{2}$ systems can be explained by the fact that, in contrast to the sintered nanoparticles, the parallel and vertical orientation of the ordered nanostructures provide well defined electron percolation paths and thus significantly reduce the diffusion distance and time constant.
\end{abstract}

\section{KEYWORDS}

Electrode, nanorods, nanotubules, sintered, efficiency

\section{Introduction}

Dye-sensitized solar cells (DSCs) have received much attention for nearly two decades now as potential low cost alternatives to conventional silicon-based $\mathrm{p}-\mathrm{n}$ junction devices [1]. Usually the working electrode in these systems is a $10 \mu \mathrm{m}$ thick $\mathrm{TiO}_{2}$ nanocrystalline film comprising a three-dimensional network of interconnected 15-20 nm sized nanoparticles sintered onto a conductive glass substrate. As opposed to silicon-based devices where the semiconductor absorbs the light and transports the released charge carriers, the two tasks are separated in a DSC system [1]. Upon illumination, a surface adsorbed panchromatic dye absorbs photons, jumps to its excited state (which lies high above the conduction band of the semiconductor), and injects an electron into the conduction band of the semiconductor resulting in charge separation. The oxidized dye is quickly reduced to its ground state by the iodide/ triiodide redox species in the electrolyte before it can recapture the injected electron. Meanwhile, the injected electron is transported in the conduction band of the semiconductor by diffusion [2] to the

Address correspondence to Nicholas.Bwana@cavehill.uwi.edu

\section{算 Springer}


charge collecting conductive glass substrate from where it performs useful work in an external circuit, before returning to the cell through the counter electrode to reduce the redox electrolyte.

Even though photoconversion efficiencies of over $11 \%$ [2] have been achieved with these systems, most dye-sensitized solar cells still deliver short-circuit current densities and open-circuit voltages much less that the theoretical maximum values [3], resulting in lower photoconversion efficiencies. The much-lessthan-optimum performances can be attributed to many factors, including degradation and desorption of the dye, leakage of the liquid electrolyte, corrosion of the $\mathrm{Pt}$ counter electrode by the iodide/ triiodide redox couple in the electrolyte, and poor semiconductor film morphology that leads to a fast recombination process between the injected electrons and the oxidized species in the redox electrolyte [4, 5]. Many efforts have been made to rectify the above problems by using new counter electrode materials $[6,7]$, by using alternative redox couples in the electrolyte $[8,9]$, by using alternative sensitizers $[10$, $11]$, and by using gel electrolytes and other types of hole conductors instead of liquid electrolytes $[12,13]$. However, very little has been done to alter the sintered electrode film structures used in these systems.

In this work we investigate the effects of the electrode film morphology on the performance of a DSC by comparing cells based on different working electrodes structures, namely (1) highly ordered arrays of $\mathrm{TiO}_{2}$ nanorods, (2) highly ordered arrays of $\mathrm{TiO}_{2}$ nanotubules, and (3) sintered $\mathrm{TiO}_{2}$ nanoparticles (Fig. 1). We investigate the effects of electrode structural uniformity and order on the charge carrier dynamics and thus on the injection, collection, and photoconversion efficiencies.

A total of 25 sample cells per electrode structure were investigated in this work. The standard backcontact used was fluoride-doped tin-oxide-coated glass (FTO), and the standard counter electrode was platinum-coated FTO. A panchromatic

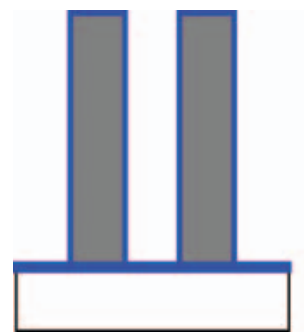

(a)

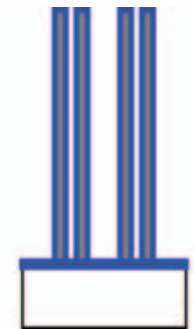

(b)

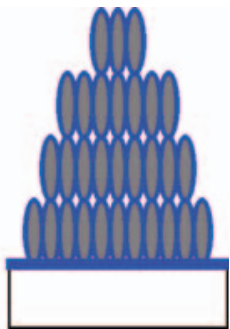

(c)
Figure 1 Schematic diagram of dye-coated (a) $\mathrm{TiO}_{2}$ nanorods, (b) $\mathrm{TiO}_{2}$ nanotubules, and (c) sintered $\mathrm{TiO}_{2}$ nanoparticles on fluorinedoped tin oxide-coated glass (FTO) substrates

sensitizer, $\mathrm{RuL}_{2}(\mathrm{NCS})_{2}$ : 2TBA (L=2, 2'-bipyridyl-4, 4'-dicarboxylic acid; TBA=tetrabutylammonium), also known as the N719 dye, was used as the standard dye in the experiments. The sensitizer is very stable and has broad range visible light absorption (Fig. 2). It has a high incident to photon conversion efficiency (IPCE) of over $80 \%$ in the wavelength range between 450 and $600 \mathrm{~nm}$. The bipyridine ligands of the dye have carboxylic acid groups that have a strong affinity for anatase $\mathrm{TiO}_{2}$ surfaces, forming $\mathrm{C}-\mathrm{O}-\mathrm{Ti}$ bonds with the surface Ti ions. The carboxylic acid group thus enhances electronic coupling between the $\pi^{*}$ orbital of the 2, 2' -bipy ligand and the Ti $3 \mathrm{~d}$ orbital manifold of the semiconductor thereby ensuring strong adsorption of the ruthenium dye complex to the nanoporous anatase $\mathrm{TiO}_{2}$ surface. The standard high boiling point iodide-based electrolyte in methoxypropionitrile (MPN), which enhances open-circuit photovoltage $\left(V_{\mathrm{oc}}\right)$ and fill factor (ff) by decreasing the rate of reduction of the triiodide in the electrolyte, was employed in this work.

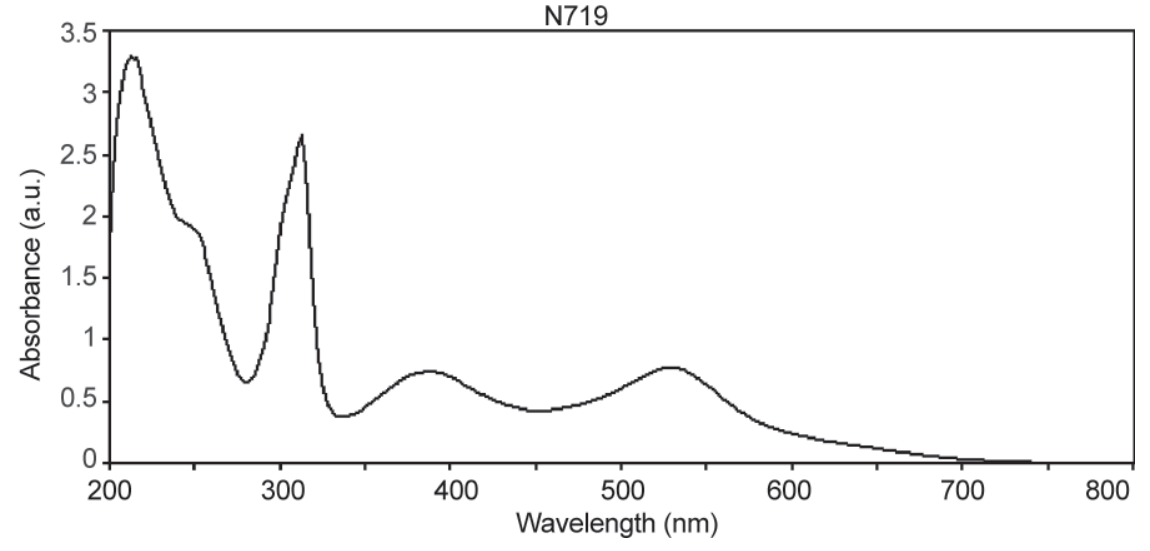

Figure 2 Absorption spectrum of the N719 dye 
Anodic alumina templates on FTO substrates prepared in-house were used to synthesize both anatase titania $\left(\mathrm{TiO}_{2}\right)$ nanotubules of desired internal diameters and nanorods by sol-gel processes [14]. The particles were then thermally bonded together to create electrical contiguity. Figure 3 shows a schematic diagram of this synthesis process. Sintered titania electrodes were prepared by screen-printing and sintering anatase $\mathrm{TiO}_{2}$ paste onto FTO substrates as has been reported elsewhere [14-16].

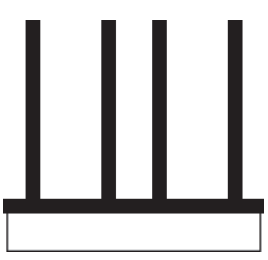

(a)

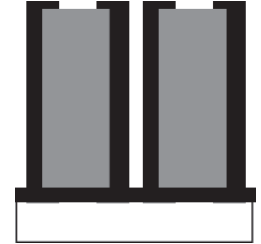

(b)

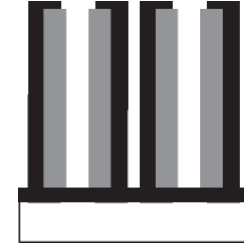

(c)
Figure 3 Schematic diagram of synthesis processes for $\mathrm{TiO}_{2}$ nanotubules and nanorods: (a) template; (b) $\mathrm{TiO}_{2}$ nanotubules deposited after $30 \mathrm{~s}$; (c) $\mathrm{TiO}_{2}$ nanorods deposited after 2 min

\section{Methodology}

\subsection{Template preparation}

Unless otherwise noted, all reagents used in this experiment were purchased from Sigma-Aldrich. Thin aluminium layers $(\sim 13 \mu \mathrm{m})$ were produced on cleaned fluorine-doped FTO substrates (Solaronix) by rf-sputtering at a beam voltage of $5 \mathrm{kV}$ for 8 h. The base chamber pressure was $1.5 \times 10^{-5}$ Torr and the argon gas pressure was $14 \times 10^{-3}$ Torr. After deposition, the samples were electropolished in a mixture of $\mathrm{H}_{3} \mathrm{PO}_{4}, \mathrm{H}_{2} \mathrm{SO}_{4}$, and $\mathrm{H}_{2} \mathrm{O}$ (4:4:2 by mass). Electropolishing considerably reduces the surface roughness of the samples, thus enhancing pore organization. Following electropolishing, the samples were cleaned with deionized water before commencing the anodization processes. The samples were anodized for $25 \mathrm{~min}$ in $0.4 \mathrm{~mol} / \mathrm{L}$ sulphuric acid at a constant cell potential of $25 \mathrm{~V}$ and constant temperature of $15{ }^{\circ} \mathrm{C}$. The resulting pores were monodisperse and ran the full length of the alumina film as shown in Fig. 4. The average pore diameter was $150 \mathrm{~nm}$.

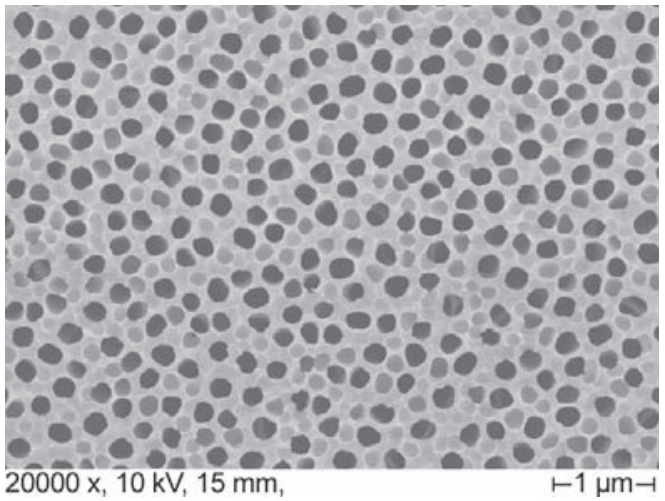

(a)

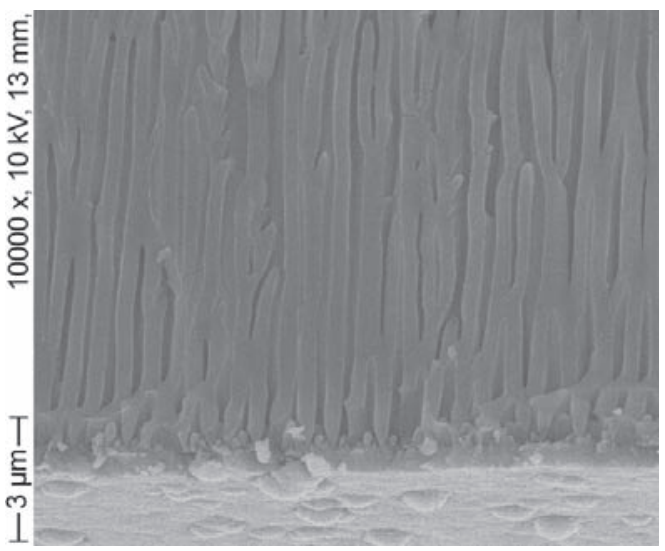

(b)

Figure 4 Top (a) and side (b) SEM images of anodic alumina templates prepared in-house showing monodisperse nanopores running the full length of the alumina film

\subsection{Synthesis of $\mathrm{TiO}_{2}$ nanotubule and nanorod electrodes}

The details of the sol-gel synthesis of $\mathrm{TiO}_{2}$ have been described elsewhere [18]. Briefly, $5 \mathrm{~mL}$ of titanium isopropoxide $\left(\mathrm{C}_{12} \mathrm{H}_{28} \mathrm{O}_{4} \mathrm{Ti}\right)$ was added to $25 \mathrm{~mL}$ of ethanol and then stirred in an ice bath. $0.5 \mathrm{~mL}$ of water and $0.5 \mathrm{~mL}$ of $0.1 \mathrm{~mol} / \mathrm{L} \mathrm{HCl}$ were added to a second $25 \mathrm{~mL}$ portion of ethanol. The $\mathrm{C}_{12} \mathrm{H}_{28} \mathrm{O}_{4} \mathrm{Ti} /$ $\mathrm{C}_{2} \mathrm{H}_{5} \mathrm{OH}$ mixture was removed from the ice bath and then the $\mathrm{C}_{2} \mathrm{H}_{5} \mathrm{OH} / \mathrm{HCl} / \mathrm{H}_{2} \mathrm{O}$ mixture was slowly added at room temperature. The resulting mixture turned milky after ca. $60 \mathrm{~s}$ (sol formation). The anodic alumina templates were immediately immersed into this solution for $30 \mathrm{~s}$ (for tubules) and for 2 min (for nanorods). After immersion, the templates were removed from the sol and dried in air for 30 min at room temperature. The templates were then 
placed in a tube furnace (in air) and the temperature ramped up to $400{ }^{\circ} \mathrm{C}$ at a constant rate of $50{ }^{\circ} \mathrm{C} / \mathrm{h}$. The templates were heated at this temperature for 6 $\mathrm{h}$ before the temperature was ramped down to room temperature. Figure 5 shows an SEM image of the synthesized nanotubules and nanorods. The tubules have an average external diameter of $\sim 150 \mathrm{~nm}$ (the same as the template diameter) and an internal diameter of $\sim 80 \mathrm{~nm}$. The nanorods have a diameter of $\sim 150 \mathrm{~nm}$. To expose the nanostructures, the anodic alumina templates were removed by immersing the samples in $6 \mathrm{~mol} / \mathrm{L} \mathrm{NaOH}$ solution for $10 \mathrm{~min}$. The resultant nanotubule and nanorod structures, standing on the FTO glass like the bristles on a brush, were then used as the working electrodes in dyesensitized solar cells.

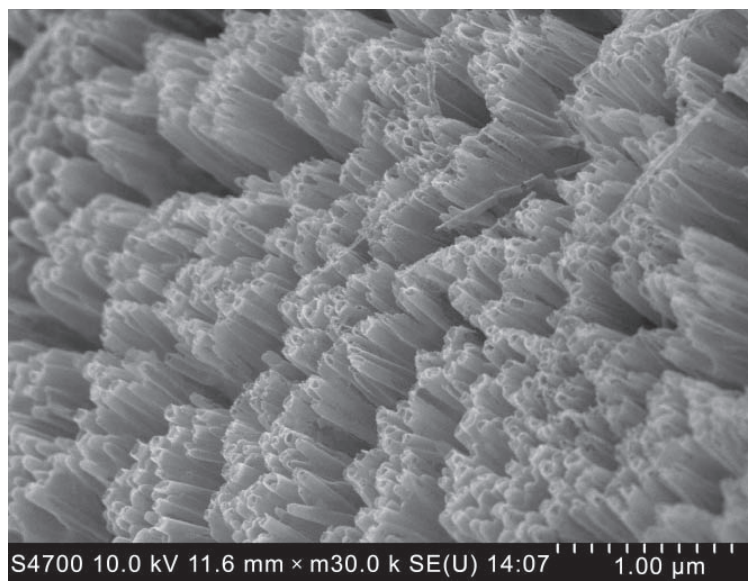

(a)

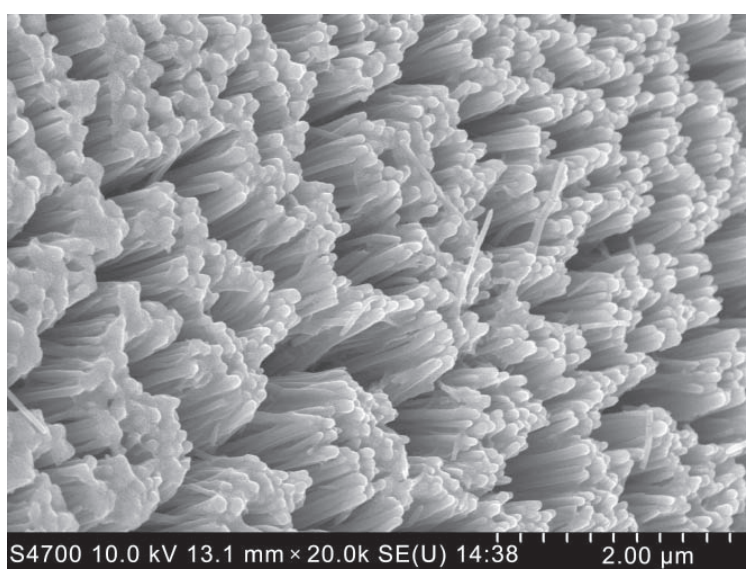

(b)

Figure $5 \mathrm{SEM}$ images of (a) $\mathrm{TiO}_{2}$ nanotubules and (b) nanorods synthesized in anodic alumina templates after removal of the templates

\subsection{DSC fabrication}

To fabricate the DSCs, the exposed electrodes were immersed overnight in $0.3 \mathrm{mmol} / \mathrm{L}$ solution of the $\mathrm{RuL}_{2}(\mathrm{NCS})_{2}$ : 2TBA ( $\mathrm{L}=2,2^{\prime}$-bipyridyl-4, $4^{\prime}$-dicarboxylic acid; TBA=tetrabutylammonium) dye (Solaronix) in acetonitrile. Since the bipyridine ligands have carboxylic acid groups that have a strong affinity for anatase surfaces, the overnight coating ensures a strong adsorption and uniform coating of the ruthenium dye complex on the nanoporous $\mathrm{TiO}_{2}$ surface. The electrolyte, Iodolyte TG-50 (Solaronix), contained $50 \mathrm{mmol} / \mathrm{L}$ of triiodide in tetraglyme, $0.5 \mathrm{~mol} / \mathrm{L} \mathrm{LiI}, 0.05 \mathrm{~mol} / \mathrm{L} \mathrm{I}_{2}, 0.6 \mathrm{~mol} / \mathrm{L}$ $\mathrm{N}$-methylbenzimidazole, $0.10 \mathrm{~mol} / \mathrm{L}$ guanidinium thiocyanate, and $0.5 \mathrm{~mol} / \mathrm{L}$ tert-butylpyridine in MPN. The counter electrodes were platinized FTO glass. The working and counter electrodes were spaced by Amosil-4 sealant (Solaronix). The electrolyte was introduced through two drilled holes on the counter electrode. The holes were then sealed with glass slides. In this work, 25 cells for each type of electrode were fabricated. The effective electrode area was $1.5 \mathrm{~cm} \times 1.5 \mathrm{~cm}$ with roughness factor of ca. 27.2 for the nanorods and ca. 62.6 for the nanotubules.

\subsection{Photovoltaic measurements}

Photoelectrochemical measurements were carried out using a $300 \mathrm{~W}$ Xenon light source that was focused to provide $1000 \mathrm{~W} / \mathrm{m}^{2}$, equivalent to one sun at air mass (AM) 1.5, at the surface of the cells. The spectral output of the lamp was matched in the region $350-800 \mathrm{~nm}$ with the aid of a Schott KG-5 sunlight filter so as to reduce the mismatch between the simulated and the true solar spectrum to less than $2 \%$. The current-voltage characteristics of the cells were determined by biasing the cells externally and measuring the generated photocurrents. The overall photoconversion efficiency $\eta$ is calculated from the integral photocurrent density $\left(J_{\mathrm{sc}}\right)$, the opencircuit photocurrent $\left(V_{o c}\right)$, the fill factor (ff) of the cell, and the intensity of the incident light $\left(I_{\mathrm{s}}\right)$ using the formula,

$$
\eta=J_{\mathrm{sc}} V_{\mathrm{oc}} \mathrm{ff} / I_{\mathrm{s}}
$$

where $I_{\mathrm{s}}=1000 \mathrm{~W} / \mathrm{cm}^{2}$ at AM 1.5, or under full 
sunlight and the fill factor (ff) is given by

$$
\mathrm{ff}=V_{\max } J_{\max } /\left(J_{\mathrm{sc}} V_{\mathrm{oc}}\right)
$$

\section{Results and discussion}

Results obtained under $100 \%$ sun irradiation are shown in Table 1 and Fig. 6. Under AM 1.5, DSCs based on $150 \mathrm{~nm}$ diameter $\mathrm{TiO}_{2}$ nanorod arrays, $\sim 13 \mu \mathrm{m}$ thick, infiltrated with N-719 dye in acetonitrile had average values of $J_{\mathrm{sc}}, V_{\mathrm{oc}}$ and $\mathrm{ff}$ equivalent to an overall photoconversion efficiency ( $\eta$ ) of $\sim 5.4 \%$. DSCs based on $\mathrm{TiO}_{2}$ nanotubule arrays of $\sim 150 \mathrm{~nm}$ external diameter, $\sim 80 \mathrm{~nm}$ internal diameter, and $\sim 13 \mu \mathrm{m}$ thickness, had average values of $J_{\mathrm{sc}}, V_{\mathrm{oc}}$, and ff equivalent to an overall photoconversion efficiency of $\sim 4.5 \%$. Finally, DSCs based on sintered $\mathrm{TiO}_{2}$ nanoparticles, $\sim 13 \mu \mathrm{m}$ thick had average values of $J_{\mathrm{sc}}, V_{\mathrm{oc}}$, and ff equivalent to an overall photoconversion efficiency of $\sim 4.7 \%$.

The high values of $V_{\text {oc }}$ observed in the nanorod systems (Table 1) can be attributed to the higher density of $\mathrm{TiO}_{2}$ nanoparticles in the nanorods than in the nanotubules and sintered nanostructures. The nanorods consist of $\mathrm{TiO}_{2}$ particles tightly packed and

Table 1 Photovoltaic measurements of DSCs based on different $\mathrm{TiO}_{2}$ working electrodes

\begin{tabular}{|c|c|c|c|c|}
\hline \multicolumn{2}{|c|}{ Measurement } & $\mathrm{TiO}_{2}$ & $\mathrm{TiO}_{2}$ & Sintered \\
\hline \multirow{4}{*}{$V_{\text {oc }}(V)$} & Max & 0.51 & 0.41 & 0.45 \\
\hline & Min & 0.45 & 0.37 & 0.39 \\
\hline & Ave & 0.48 & 0.39 & 0.43 \\
\hline & STD & 0.02 & 0.01 & 0.02 \\
\hline \multirow{4}{*}{$\begin{array}{c}J_{s c} \\
\left(m A / \mathrm{cm}^{2}\right)\end{array}$} & Max & 16.7 & 17.4 & 14.4 \\
\hline & Min & 15.1 & 16.4 & 13.5 \\
\hline & Ave & 16 & 17 & 14 \\
\hline & STD & 0.42 & 0.22 & 0.24 \\
\hline \multirow{4}{*}{$\mathrm{ff}$} & Max & 0.74 & 0.70 & 0.82 \\
\hline & Min & 0.68 & 0.66 & 0.73 \\
\hline & Ave & 0.70 & 0.68 & 0.79 \\
\hline & STD & 0.02 & 0.01 & 0.02 \\
\hline \multirow{4}{*}{$\eta(\%)$} & Max & 5.8 & 4.8 & 4.9 \\
\hline & Min & 4.8 & 4.3 & 4.5 \\
\hline & Ave & 5.4 & 4.5 & 4.7 \\
\hline & STD & 0.23 & 0.13 & 0.09 \\
\hline
\end{tabular}

bonded together in uniform structural arrangements, orthogonal to the surface of the substrate. This arrangement ensures more particles per unit volume than in the other two structures. Also, since the inner $\mathrm{TiO}_{2}$ particles are shielded by the outer ones from back reaction ( $\mathrm{I}_{3}^{-}+2 \mathrm{e}^{-} \rightarrow 3 \mathrm{I}^{-}$) with the oxidized species in the redox electrolyte, the rate of recombination at open-circuit in these structures is reduced. The sintered nanoparticles are randomly arranged and the particles are exposed to oxidized species in the liquid electrolyte, which percolates throughout the structure. This enhances the back reaction at open-circuit and thus leads to lower $V_{\text {oc }}$ values. The lowest $V_{\text {oc }}$ values were observed in cells based on $\mathrm{TiO}_{2}$ nanotubules. This can be explained by the fact that of the three types of electrodes, those based on nanotubules had the highest surface area in contact with the redox electrolyte. Since at open-circuit all injected electrons must eventually recombine with the holes in the redox electrolyte, the reduced distance (thin walls) between the trapped electrons in the $\mathrm{TiO}_{2}$ trap states and the holes in the redox electrolyte augments this process; at open-circuit, detrapped electrons quickly recombine with the holes before they can be trapped again by nearby $\mathrm{TiO}_{2}$ particles. This limitation can be corrected by using thicker and longer nanotubules which will limit recombination at open-circuit by shielding the electrons trapped in the trap states of the inner $\mathrm{TiO}_{2}$ particles from the holes in the electrolyte.

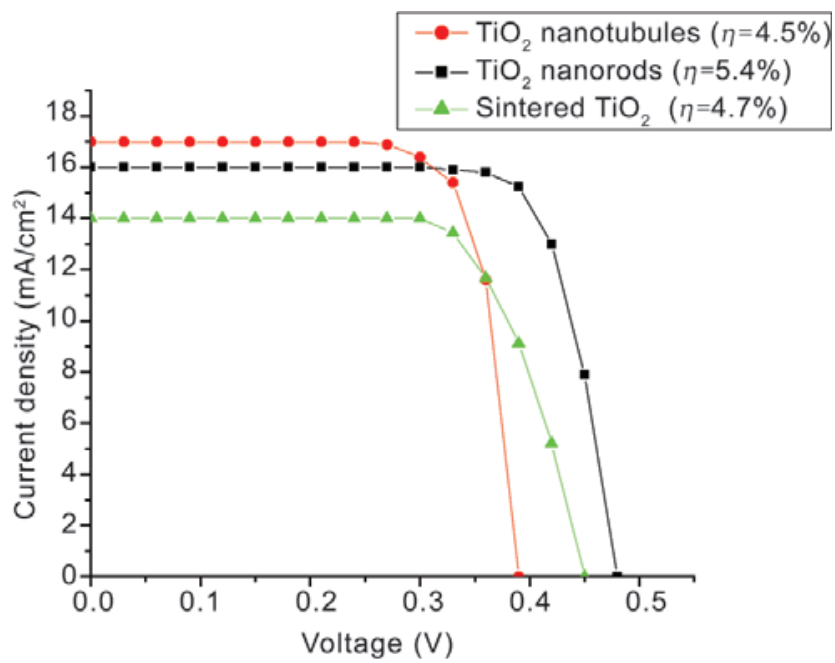

Figure 6 Photocurrent-voltage curves of DSCs based on different $\mathrm{TiO}_{2}$ working electrodes 
It is evident from the data above that cells based on ordered nanostructures give higher $J_{\mathrm{sc}}$ values than those based on sintered $\mathrm{TiO}_{2}$ nanoparticles. High $J_{\text {sc }}$ values indicate high electron collection efficiencies which in turn indicate faster electron diffusion rates. The ordered nanostructures act like single crystalline structures and thus permit vectorial charge transfer from the solution to the conductive substrate, thereby reducing losses incurred by charge hopping across nanoparticulate grain boundaries [14-16]. Each nanotubule or nanorod makes it more difficult for an electron to jump outside the nanostructure than to stay within the structure during diffusion; this explains the high collection efficiencies and thus high short-circuit photocurrents. The superior electron transport conduits allow the use of thicker films to improve light absorption without sacrificing electrical properties per increased charge carrier recombination [17], and thus improve the absorption of low-energy photons in the red and infrared regions.

The highest $J_{\mathrm{sc}}$ values were achieved with cells based on $\mathrm{TiO}_{2}$ nanotubules. It is possible that the high surface area of the $\mathrm{TiO}_{2}$ nanoparticles in contact with the electrolyte could be a contributing factor here. This could mean that the rate of dye oxidation (by electron injection) and reduction (by the redox electrolyte) is enhanced due to reduced distances of the processes involved (thin tubule walls). These processes enhance the rate of collection which in turn translates into high $J_{\mathrm{sc}}$ values. For $\mathrm{TiO}_{2}$ nanorods, the high $J_{\mathrm{sc}}$ values observed can be explained by the fact that, in addition to faster diffusion rates, the inner $\mathrm{TiO}_{2}$ nanoparticles are shielded from recombination with the oxidized species in the electrolyte by the outer nanoparticles. This means that injected electrons could be collected rapidly before recombination occurs. Systems based on sintered nanoparticles had the lowest values of $J_{\mathrm{sc}}$ possibly because of the increased number of trap sites and the random zigzag motion (slow) of the injected electrons to the back contact [19]. This slow diffusion process enhances recombination with the oxidized species in the electrolyte which percolates throughout the structure.

Overall, DSCs based on $\mathrm{TiO}_{2}$ nanorods showed the best performances with the highest values of $V_{\text {oc }}$ and photoconversion efficiencies. These remarkable performances are attributed to the parallel and vertical orientation of the nanorods which: (1) considerably reduce the trap site effects seen in sintered films by providing a short electron diffusion path to the FTO collecting surface, (2) considerably reduce the trapping and detrapping events synonymous with the electron diffusion motion to the FTO collecting surface by reducing the number of trap sites that the electrons encounter before reaching the electrode, (3) considerably reduce the diffusion time constant in the DSC systems by reducing the diffusion distance between the point of electron injection into the $\mathrm{TiO}_{2}$ conduction band and the point of electron collection on the FTO glass substrates, and (4) reduce the band bending effects of the semiconductor conduction band caused by accumulation of electron in the deep trap states by enhancing charge collection, and by limiting the thickness of the semiconductor whilst maintaining the good surface to volume ratio vital for efficient injection. The thickness of the $\mathrm{TiO}_{2}$ is small enough to accommodate only a few layers of material, thus reducing the number of trap states the injected electrons have to pass though before reaching that the collecting substrate. As mentioned earlier, this faster rate of diffusion and collection enhances the value of $J_{\mathrm{sc}}$ and thereby increases the photoconversion efficiency.

\section{Conclusions}

We have shown that dye-sensitized solar cells based on ordered arrays of $\mathrm{TiO}_{2}$ nanostructures have higher charge collection efficiencies and thus higher short-circuit current densities than those based on sintered $\mathrm{TiO}_{2}$ nanoparticles. This remarkable performance is mainly attributed to the reduced number of trap sites and consequently, fewer trapping and detrapping events synonymous with systems based on sintered nanostructured electrodes. The ordered nanostructures provide well defined electron diffusion paths to the charge collectors and thus reduce the diffusion distances and time constants. Future work will focus on increasing the thickness and lengths of the nanostructures to improve the open-circuit photovoltage, increase the 
surface area of the electrode, and further improve the photoconversion efficiency. In the future we propose to make DSCs based on ordered arrays of $\mathrm{TiO}_{2-}$ coated titanium nanorod electrodes. With these we aim to achieve very high efficiencies based on very high short-circuit photocurrent values and very high charge collection efficiencies.

\section{References}

[1] O’Regan, B.; Grätzel, M. A low-cost, high-efficiency solar cell based on dye-sensitized colloidal $\mathrm{TiO}_{2}$ films. Nature 1991, 353, 737-740

[2] Grätzel, M. Solar energy conversion by dye-sensitized photovoltaic cells. Inorg. Chem. 2005, 44, 6841-6851

[3] Mor, G. K.; Shankar, K.; Paulose, M.; Varghese, O. K.; Grimes, C. A. Use of highly-ordered $\mathrm{TiO}_{2}$ nanotube arrays in dye-sensitized solar cells. Nano Lett. 2006, 6, 215-218.

[4] Park, N. G.; Schlichthrol, G.; van de Lagemaat, J.; Cheong, H. M.; Mascarenhas, A.; Frank, A. J. Dyesensitized $\mathrm{TiO}_{2}$ solar cells: Structural and photoelectrochemical characterization of nanocrystalline electrodes formed from hydrolysis of $\mathrm{TiCl}_{4}$. J. Phys. Chem. B 1999, 103, 3308-3314

[5] Grünwald, R.; Trbutsch, H. Mechanisms of instability in Ru-based dye sensitization solar cells. J. Phys. Chem. B 1997, 101, 2564-2575

[6] Kay, A.; Grätzel, M. Low cost photovoltaic modules based on dye sensitized nanocrystalline titanium dioxide and carbon powder. Sol. Energy Mater. Sol. Cells 1996, 44, 99-117

[7] Suzuki, K.; Yamaguchi, M.; Kumagai, M.; Yanagida, S. Application of carbon nanotubes to counter electrodes of dye-sensitized solar cells. Chem. Lett. 2003, 32, 2829

[8] Oskam, G.; Bergeron, B. V.; Meyer, G. J.; Searson, P. C. Pseudohalogens for dye-sensitized $\mathrm{TiO}_{2}$ photoelectrochemical cells. J. Phys. Chem. B 2001, 105, 68676873

[9] Nusbaumer, H.; Moser, J. E; Zakeeruddin, S. M.; Nazeeruddin, M. K.; Grätzel, M. Co"(dbbip) ${ }_{2}^{2+}$ complex rivals tri-iodide/iodide redox mediator in dye-sensitized photovoltaic cells. J. Phys. Chem. B 2001, 105, 1046110464

[10] Ferrere, S.; Gregg, B. A. Photosensitization of $\mathrm{TiO}_{2}$ by [Fe" $\left(2,2^{\prime} \text {-bipyridine-4,4'-dicarboxylic acid }\right)_{2}(\mathrm{CN})_{2}$ ]: Band selective electron injection from ultra-short-lived excited states. J. Am. Chem. Soc. 1998, 120, 843-844

[11] Hou, Y. J.; Xie, P. H.; Zhang, B. W.; Cao, Y.; Xiao, X. R.; Wang, W. B. Influence of the attaching group and substituted position in the photosensitization behavior of ruthenium polypyridyl complexes. Inorg. Chem. 1999, 38, 6320-6322

[12] Kumara, G. R. A.; Kaneko, S.; Okuya, M.; Tennakone, K. Fabrication of dye-sensitized solar cells using triethylamine hydrothiocyanate as a Cul crystal growth inhibitor. Langmuir 2002, 18, 10493-10495

[13] O'Regan, B.; Lenzmann, F.; Muis, R.; Wienke, J. A solidstate dye-sensitized solar cell fabricated with pressuretreated $\mathrm{P} 25-\mathrm{TiO}_{2}$ and CuSCN: Analysis of pore filling and I-V characteristics. Chem. Mater. 2002, 14, 5023-5029

[14] Nazeeruddin, M. K.; Péchy, P.; Renouard, T.; Zakeeruddin, S. M.; Humphrey-Baker, R.; Comte, P.; Liska, P.; Cevey, L.; Costa, E.; Shklover, V.; Spiccia, L.; Deacon, G. B.; Bignozzi, C. A.; Grätzel, M.; Engineering of efficient panchromatic sensitizers for nanocrystalline $\mathrm{TiO}_{2}$-based solar cells. J. Am. Chem. Soc. 2001, 123, 1613-1624

[15] Hulteen, J. C.; Martin, C. R. A general template-based method for the preparation of nanomaterials. J. Mater. Chem. 1997, 7, 1075-1087

[16] Tenne, R.; Rao, C. N. R. Inorganic nanotubes. Phil. Trans. R. Soc. Lond. A Math. Phys. Eng. Sci. 2004, 362, 20992125

[17] Grätzel, M. Conversion of sunlight to electric power by nanocrystalline dye-sensitized solar cells. J. Photochem. Photobiol. A: Chem. 2004, 164, 3-14

[18] Adachi, M.; Murata, Y.; Okada, I.; Yoshikawa, S. Formation of titania nanotubes and applications for dyesensitized solar cells. J. Electrochem. Soc. 2003, 150, G488-G493

[19] de Jong, P. E.; Vanmaekelbergh, D. Investigation of the electronic transport properties of nanocrystalline particulate $\mathrm{TiO}_{2}$ electrodes by intensity-modulated photocurrent spectroscopy. J. Phys. Chem. B 1997, 101, 2716-2722 